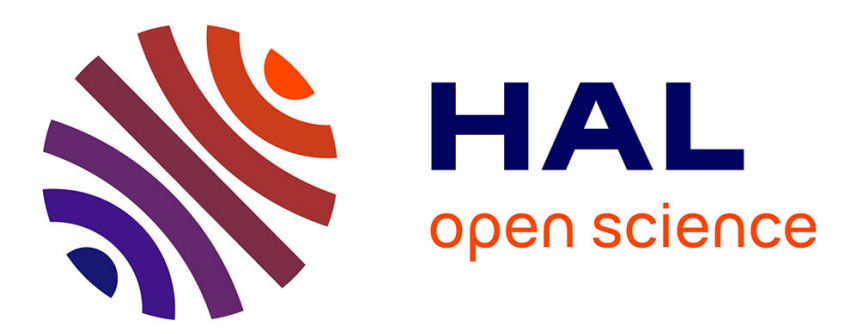

\title{
A numerical investigation of the influence of large-scale winds on sea-breeze and inland-breeze-type circulations
}

Peter Bechtold, Jean-Pierre Pinty, Patrick Mascart

\section{To cite this version:}

Peter Bechtold, Jean-Pierre Pinty, Patrick Mascart. A numerical investigation of the influence of large-scale winds on sea-breeze and inland-breeze-type circulations. Journal of Applied Meteorology, 1990. hal-01988009

\author{
HAL Id: hal-01988009 \\ https://hal.uca.fr/hal-01988009
}

Submitted on 9 Jun 2021

HAL is a multi-disciplinary open access archive for the deposit and dissemination of scientific research documents, whether they are published or not. The documents may come from teaching and research institutions in France or abroad, or from public or private research centers.
L'archive ouverte pluridisciplinaire HAL, est destinée au dépôt et à la diffusion de documents scientifiques de niveau recherche, publiés ou non, émanant des établissements d'enseignement et de recherche français ou étrangers, des laboratoires publics ou privés. 


\title{
A Numerical Investigation of the Influence of Large-Scale Winds on Sea-Breeze- and Inland-Breeze-type Circulations
}

\author{
Peter Bechtold, Jean-PierRe Pinty AND Patrick Mascart \\ Observatoire de Physique du Globe de Clermont-Ferrand, Laboratoire de Météorologie Physique, \\ Université Blaise Pascal, 63170 Aubière, France
}

(Manuscript received 29 October 1990, in final form 22 February 1991)

\begin{abstract}
A two-dimensional mesoscale model is used to study the influence of large-scale background winds on seabreeze- and inland- (vegetation) breeze-type circulations. It is found that the intensity (vertical velocity) of the sea breeze is at its maximum when the propagation speed of the sea-breeze front is canceled out by the background wind speed. Using the gravity current theory, we get a fair prediction of this optimum background wind value.

The intensity and extent of the inland breeze, forming between a forest and an adjacent crop area, do not vary over a large range of values for the large-scale wind. The location of the ascending branch of the inland breeze is stationary with respect to the interface between the two vegetation types. It is suggested that it is not friction drag but rather turbulent mixing that leads to a more horizontally uniform boundary layer and which is responsible for the different behavior of the inland breeze, i.e., a weak and nonpropagating circulation.
\end{abstract}

\section{Introduction}

Some 30 years of interest in the sea-breeze (SB) phenomenon resulted in numerous theoretical and numerical studies. The first studies of this phenomenon as a function of synoptic conditions, i.e., large-scale winds and atmospheric stability, were made by Defant (1951), Estoque (1962), and later Walsh (1974). Yan and Anthes (1987), and in a recent article Dalu and Pielke (1989), emphasized the importance of the Coriolis parameter and the atmospheric stability conditions on the intensity and horizontal extent of the SB circulation. Their results are in agreement with the linear theory of Rotunno (1983). In a general study, Arrit (1989) covered all of these aspects and also took the effect of coastline curvature into account. However, to our knowledge only Walsh (1974) and Savijärvi and Alestalo (1988) reported a strong circulation (vertical velocity) in the presence of offshore background winds $<7 \mathrm{~m} \mathrm{~s}^{-1}$.

The following study will show that thermally driven circulations of the SB and inland-breeze type reveal some interesting features if we characterize the intensity of the circulation by the maximum of the vertical velocity. The term inland breeze is used here for a circulation induced by surface inhomogeneities, such as vegetation cover and soil wetness (e.g., Ookouchi et al. 1984; Segal et al. 1988; Pinty et al. 1989). The study

Corresponding author address: Peter Bechtold, Observatoire de Physique du Globe de Clermont-Ferrand, Laboratoire de Meteorologie Physique, B.P. 45, Universite Blaise Pascal, F-63170, Aubiere France. focuses on two questions: 1) what are the mechanisms leading to an intensification of the SB circulation in the presence of moderate offshore winds, and 2) can this feature also be observed for an inland-breeze-type circulation. These questions are addressed using a twodimensional version of the hydrostatic meso- $\beta$ model of Nickerson et al. (1986). This model includes the interactive soil-vegetation scheme of Mahfouf et al. (1987) and Pinty et al. (1989).

In the SB case, the effects of changes in the largescale background wind are first investigated. In the following we keep the wind direction cross-coast and examine the vertical velocity of the breeze flow as a function of the synoptic wind intensity. The gravity current theory will help us to interpret the propagation of the breeze circulation and to explain the observed phenomena. In a second part of the study we treat an inland-breeze case characterized by a circulation forming between a forest and an adjacent crop area. Finally, we present a comparison with the SB case and discuss the role of atmospheric turbulence.

\section{The sea-breeze case}

\section{a. Reference simulation}

A detailed model description is given in Nickerson et al. (1986) and Pinty et al. (1989). The 2D model domain is $420 \mathrm{~km}$ wide with a grid space of $10 \mathrm{~km}$. The vertical grid includes $16 \sigma$ levels, given according to:

$$
\sigma=\frac{\left(4 \nu-\nu^{4}\right)}{3}=\frac{\left(P-P_{\text {top }}\right)}{\Pi} ; \quad \Pi=P_{s}-P_{\text {top }}
$$


TABLE 1a. Initial conditions for the reference simulation.

\begin{tabular}{llll}
\hline \hline Initial profile: & & Surface properties: \\
Geostrophic wind & $U_{g}=0 V_{g}=0.1 \mathrm{~m} \mathrm{~s}^{-1}$ & Soil temperature & $288.15 \mathrm{~K}$ \\
Thermal stratification & $\partial \theta / \partial z=3.3 \mathrm{~K} \mathrm{~km}^{-1}$ & Sea temperature & $288.15 \mathrm{~K}$ \\
Relative humidity & $40 \%$ at all levels & Atmospheric pressure & $1013.25 \mathrm{hPa}$ \\
Boundary-layer height & $200 \mathrm{~m}$ & Sea roughness & $0.032 u_{*}^{2} \mathrm{~g}^{-1}$ \\
Temporal discretization: & & Soil properties: & \\
Initial time & $0600 \mathrm{LST} 21$ March & Soil type & Sand \\
Simulation time & $24 \mathrm{~h}$ & Roughness length & $z_{0}=0.05 \mathrm{~m}$ \\
Time step & $10 \mathrm{~s}$ & Albedo & 0.2 \\
Spatial discretization: & & Moisture content & $0.08(0.4=\mathrm{saturation})$ \\
Horizontal grid size & $10 \mathrm{~km}$ & Heat capacity & $1463 \mathrm{~J}(\mathrm{~kg} \mathrm{~K})^{-1}$ \\
Number of grid points & $43 \mathrm{or} 63$ & & \\
Number of vertical levels & 16 & & \\
\hline
\end{tabular}

The surface pressure $P_{s}$ is $1013.25 \mathrm{hPa}$, the model top $P_{\text {top }}$ is set at $300 \mathrm{hPa}$. The first model level is located at about $z=15 \mathrm{~m}$. The land and sea, respectively, occupy 22 and 21 grid points. For some of the simulations it was necessary to extend the horizontal model domain to 63 points in order to avoid boundary effects. The model is initialized for 0600 LST 21 March at a latitude of $40^{\circ} \mathrm{N}$ with soil and sea temperature uniform, $T_{\text {soil }}=T_{\text {sea }}=15^{\circ} \mathrm{C}$ at this time. The thermal stratification corresponds to the standard atmosphere $(\partial \theta / \partial z$ $=3.3 \mathrm{~K} \mathrm{~km}^{-1}$, the relative humidity is $40 \%$ and constant with altitude. The sea surface temperature remains unchanged during the simulation, but soil temperature and humidity are computed by an energy budget technique every six time steps $(60 \mathrm{~s})$. The largescale background winds are defined by prescribing a geostrophic wind constant with height and time. The equations for the horizontal wind components are written in the usual form (Nickerson et al. 1986):

$$
\begin{aligned}
& \frac{\partial \Pi U}{\partial t}=-\frac{\partial}{\partial x}(\Pi U U) \\
&-\frac{1}{\sigma^{\prime}} \frac{\partial}{\partial \nu}\left(\sigma^{\prime} \Pi U \nu\right)+\Pi f\left(V-V_{g}\right)+F_{u} \\
& \quad+\left(\Phi-\frac{R T_{v} \sigma \Pi}{P}\right) \frac{\partial \Pi}{\partial x}-\frac{\partial}{\partial x}(\Pi \Phi) \\
& \frac{\partial \Pi V}{\partial t}=-\frac{\partial}{\partial x}(\Pi V U)-\frac{1}{\sigma^{\prime}} \frac{\partial}{\partial \nu}\left(\sigma^{\prime} \Pi V i\right) \\
&-\Pi f\left(U-U_{g}\right)+F_{v},
\end{aligned}
$$

the vertical velocity is calculated by the hydrostatic equation. The model further includes prognostic equations for the equivalent potential temperature, the specific humidity and the turbulent kinetic energy (order 1.5 closure ). The last one in order to compute the turbulent mixing terms $F_{u}$ and $F_{v}$ (Therry and Lacarrere 1983). Symbols are explained in the Appendix. Table la gives the initial conditions which correspond essentially to those used by Arrit (1989). The SB simulations include four numerical experiments (Table 1b). Each of these experiments is performed by comparing a series of numerical runs made with different large-scale winds (e.g., ranging from -5 to $+5 \mathrm{~m} \mathrm{~s}^{-1}$ in experiment SB1). In experiments 1 (SB1) to 3 (SB3) only the geostrophic wind and atmospheric stability differ from the reference simulation, whereas in SB4 a higher horizontal model resolution of $5 \mathrm{~km}$ is used.

\section{b. Varying the geostrophic wind direction}

The distribution of the land and the sea over the model domain is shown in Fig. 1. The horizontal and vertical extent of the SB circulation are shown by the isotachs of the horizontal wind $U$ at 1500 LST for the reference zero wind case (Fig. 1a), and for a $5 \mathrm{~m} \mathrm{~s}^{-1}$ offshore geostrophic wind case (Fig. 1b). This representation reveals two characteristics of the SB system in the presence of a geostrophic wind: (i) a downstream displacement of the circulation with the geostrophic wind, and (ii) the asymmetry of the circulation. It is worth noting that a linear model could not reproduce asymmetric circulations.

TABLE 1b. Sea-breeze simulations.

\begin{tabular}{cllll}
\hline \hline Experiment & \multicolumn{1}{c}{$U_{g}\left(\mathrm{~m} \mathrm{~s}^{-1}\right)$} & $V_{g}\left(\mathrm{~m} \mathrm{~s}^{-1}\right)$ & $N=\left(\frac{g}{\theta} \frac{\partial \theta}{\partial z}\right)^{1 / 2}\left(\mathrm{~s}^{-1}\right)$ & $\begin{array}{c}\text { Horizontal } \\
\text { grid size }(\mathrm{km})\end{array}$ \\
\hline SB1 & 0 & $-5,0.1,5$ & 0.01 & 10 \\
& $-5,5$ & 0 & & 10 \\
SB2 & -5 & 5 & 0.01 & 10 \\
SB3 & $-5,0,2,5,7,9,10,12$ & 0 & 0.005 & 5 \\
SB4 & $-5,0,2,5,7,10,15$ & 0 & 0.01 & \\
\hline
\end{tabular}



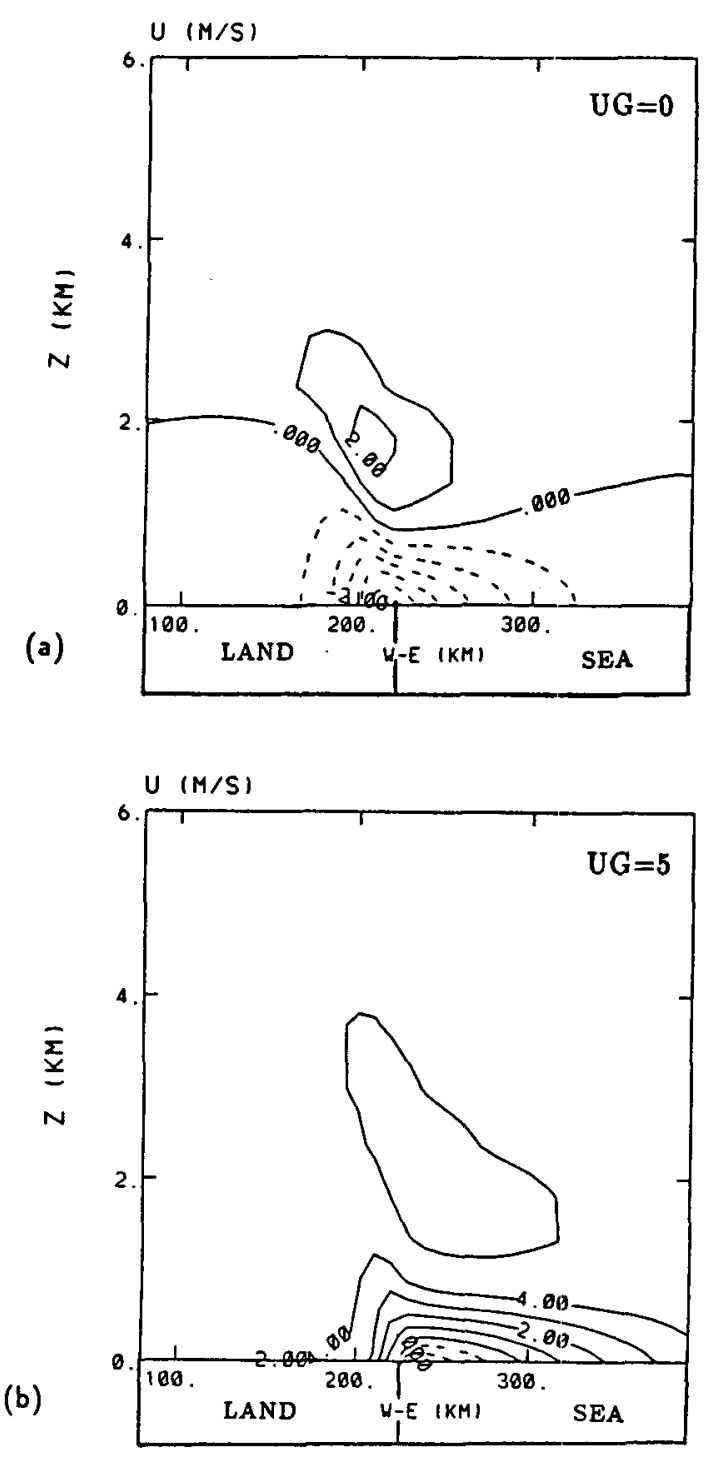

FIG. 1. Isotachs of the horizontal wind speed $U$ in meters per second at 1500 LST with (a) $U_{g}=0 \mathrm{~m} \mathrm{~s}^{-1}$ and (b) $U_{g}=5 \mathrm{~m} \mathrm{~s}^{-1}$.

The results of experiment SB1 are presented in Fig. 2 , which shows hodographs of the horizontal wind speed at the coastline and at the first model level ( $z$ $=15 \mathrm{~m}$ ) as a function of the direction of the geostrophic wind. The reference no-wind case reveals a quasi-circular hodograph (center frame, Fig. 2f). A deformation of this circle can be expected as a function of the geostrophic wind. We see (Figs. 2a,d) that cross-coast background winds lead to distorted hodographs with an intensification of the SB for a $5 \mathrm{~m} \mathrm{~s}^{-1}$ offshore geostrophic wind and a weakening when there is a 5 $\mathrm{m} \mathrm{s}^{-1}$ onshore wind. Coast-parallel winds (Figs. 2c,e) scarcely alter the intensity of the circulation. However, we find a frictional effect at the coastline, that is, a frictional drag that deviates the low-level coast-parallel winds and leads to the disappearance of the land breeze for a $5 \mathrm{~m} \mathrm{~s}^{-1}$ southern geostrophic wind (Fig. 2c). Finally, the more complex case of a southeasterly geostrophic wind (Fig. 2b) is essentially a superposition of the more simple situations in Fig. 2a (easterly geostrophic wind) and Fig. 2c (southerly geostrophic wind).

Our results agree well with those obtained by Savijärvi and Alestalo (1988) in spite of the fact that those authors considered the more complex case of a flow over a lake. In the following sections we restrict the study to the case of cross-coast winds and study the intensity (vertical velocity) of the circulation as a function of offshore and onshore geostrophic winds. The vertical velocity is chosen as a measure for the intensity of the breeze because (i) the vertical velocity triggers cloud formation and can eventually lead to rainfall, and (ii) because it is a very sensitive parameter representing not the mean wind field, but rather its horizontal divergence.

\section{c. Cross-coast winds}

According to the experiments SB2 and SB3, we varied the geostrophic wind component $U_{g}$ between -5 (onshore wind) and $12 \mathrm{~m} \mathrm{~s}^{-1}$ (offshore wind); the component $V_{g}$ was kept to zero. Figure 3 shows the maximum vertical velocity as a function of $U_{g}$ for the two atmospheric stability conditions used. We are especially interested in the shape of the graph and not in the absolute values of the vertical velocity because these depend on the horizontal grid size used in the model. We see that in both cases there exists a pronounced maximum of the vertical velocity for 5-6 $\mathrm{m} \mathrm{s}^{-1}$ offshore winds. In the more stable case, characterized by a Brunt-Väisälä frequency $N=0.01 \mathrm{~s}^{-1}$, the intensity weakens sharply for stronger offshore winds. The maximum vertical velocity attains 11.5 $\mathrm{cm} \mathrm{s}^{-1}$. The same simulation with the stability reduced by a factor of 2 shows maximum vertical velocities of only about $8 \mathrm{~cm} \mathrm{~s}^{-1}$ and a more symmetrical graph. A less stable atmosphere leads to weaker maximum vertical velocities, but the circulation, defined in a vertical plane by the integral $L^{-1} \oint \mathbf{U} d \mathbf{l}$, remains unchanged because the breeze extends over a larger vertical domain (Rotunno 1983). The main result obtained at this point is because a weak offshore wind increases the breeze circulation, whereas a stronger wind decreases it. The maximum breeze intensity occurs with a $5 \mathrm{~m} \mathrm{~s}^{-1}$ offshore wind. The following sections try to provide some insight into the physical processes leading to this rather unexpected intensification in the low wind case.

\section{d. Trajectories associated with the $S B$}

Trajectories are evaluated with a predictor-corrector scheme in $x, y, \nu$ coordinates. The time step is $100 \mathrm{~s}$. The necessary interpolations are bilinear. Figure 4 shows 12-h trajectories between 0900 and 2100 LST. 

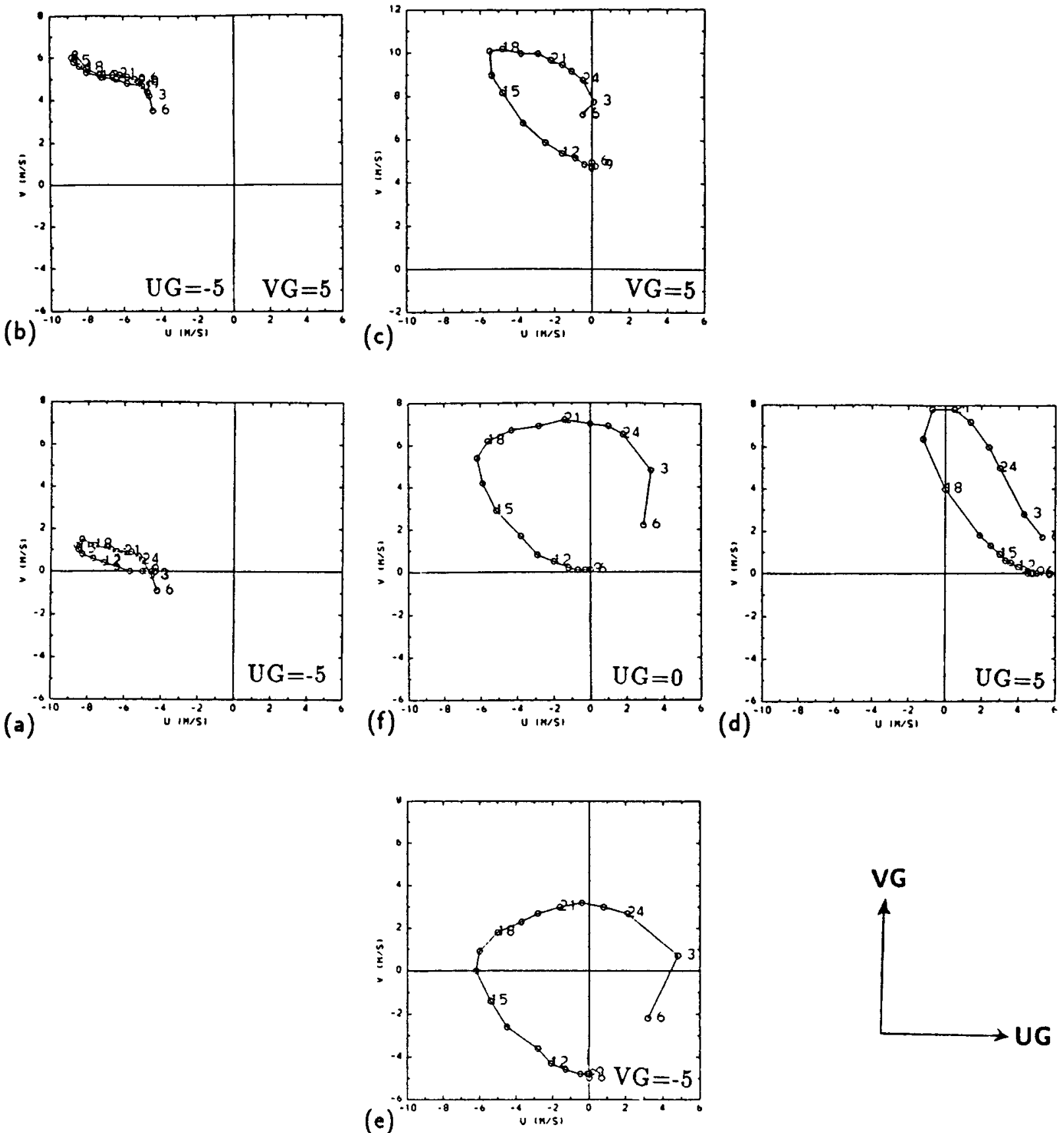

Fig. 2. Hodographs of the horizontal wind at the coastline and at the first model level $(z=15 \mathrm{~m})$ for different values of the geostrophic wind. On each curve, time is indicated every $3 \mathrm{~h}$.

Trajectories are plotted in a vertical section for different offshore wind cases. Figures $4 a, b$ show actual trajectories, whereas, the trajectories shown in Figs. 4c,d are relative to the geostrophic wind. The no-wind case (Fig. 4a) displays a closed circulation. However, in the presence of a slight offshore wind (Fig. 4b) the trajectories seem to be deviated upward near the coastline $(x$ $=210 \mathrm{~km}$ ) over an obstacle corresponding to the low- level maritime inflow, which acts like a gravity current (schematically depicted by the hatched area of Fig. 4b). Figures $4 \mathrm{c}$,d show the relative trajectories obtained for the same simulations by subtracting the geostrophic wind from the computed wind field. Comparing Fig. 4a (no-wind case) and Fig. 4d (5 $\mathrm{m} \mathrm{s}^{-1}$ geostrophic wind), we notice a significant intensification of the breeze circulation, stronger vertical velocities and a 


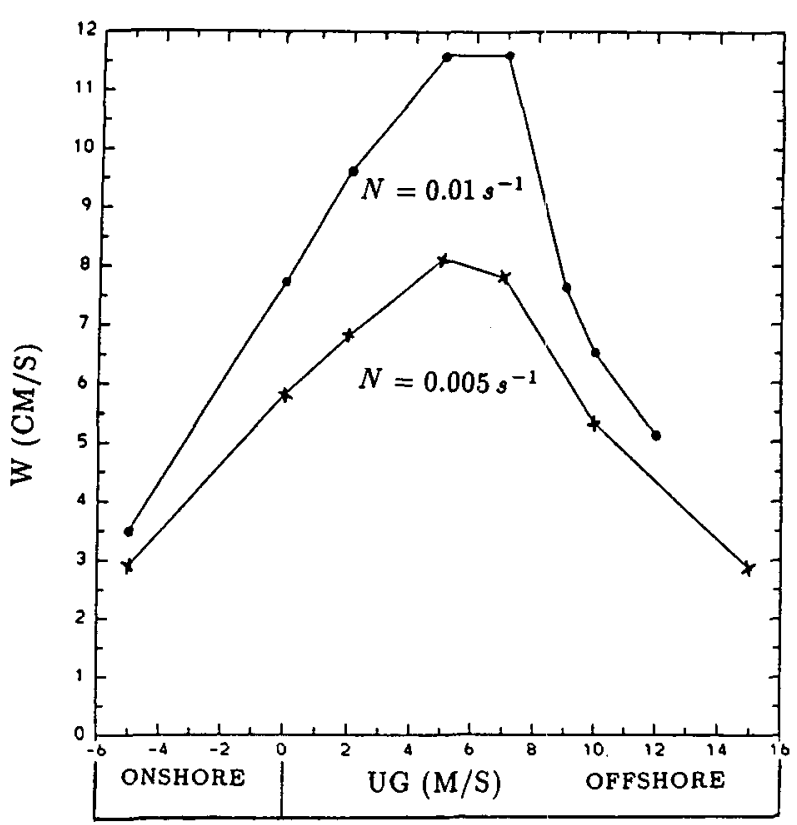

Fig. 3. Vertical velocity in centimeters per second as a function of the geostrophic wind $U_{g}$ for two different values of the BruntVäisälä frequency $N$.

greater vertical extent of the flow. We also notice a sharpening of the ascending branch of the flow, with trajectories being essentially vertical in the $5 \mathrm{~m} \mathrm{~s}^{-1}$ wind case. This last case is therefore characterized by the stationarity of the SB circulation relative to the coast and the formation of a SB front. The stationarity of the SB circulation with respect to the coast in the presence of a $5 \mathrm{~m} \mathrm{~s}^{-1}$ offshore wind leads us to the assumption that the propagation speed of the SB front (gravity current) is of the order of $5 \mathrm{~m} \mathrm{~s}^{-1}$.

\section{e. SB propagation and gravity current theory}

In order to determine numerically the propagation speed of the SB circulation we have redone model simulations (experiment SB4) using a horizontal domain of 63 points and a grid spacing of $5 \mathrm{~km}$ with the same model time step of $10 \mathrm{~s}$ for 0,5 , and $10 \mathrm{~m} \mathrm{~s}^{-1}$ offshore geostrophic wind cases (Fig. 5). The SB front is visualized with the aid of the horizontal virtual temperature gradient, $\partial \theta_{v} / \partial x$ at $z=15 \mathrm{~m}$. Figure 5 shows the evolution of $\partial \theta_{v} / \partial x$ between 1200 and 2100 LST. In the no-wind case (Fig. 5a) at 1200 LST, the SB front is located close to the coastline as indicated by a welldefined minimum of $\partial \theta_{v} / \partial x$ of the order of -0.5 $\mathrm{K} \mathrm{km}^{-1}$. The temperature gradient minimum, visualizing the SB front, advances $100 \mathrm{~km}$ inland between 1500 and 1800 LST, corresponding to a propagation speed of $5.5 \mathrm{~m} \mathrm{~s}^{-1}$. It reaches the left boundary of the model domain at 2100 LST. During the same period, the intensity of the $\partial \theta_{v} / \partial x$ minimum weakens, due to the turbulent mixing over land (SB front erosion from below). It should further be remarked that Fig. 5 reveals two temperature gradient extremes over the model domain. The stronger one is due to the SB front while the other one is fixed at the coastline and probably reflects an internal boundary layer structure between land and water.

The $5 \mathrm{~m} \mathrm{~s}^{-1}$ wind case exhibits a remarkably different behavior from the first case. The temperature contrast is sharpened during the early afternoon. There is no mixing between the different air masses and $\partial \theta_{v} / \partial x$ reaches a value $-0.7 \mathrm{~K} \mathrm{~km}^{-1}$. The SB front is quasi stationary at the coastline, i.e., the propagation speed of the SB front equals the geostrophic wind. Finally, a $10 \mathrm{~m} \mathrm{~s}^{-1}$ offshore wind (Fig. 5c) transports the circulation over the sea and does not allow for the formation of a sharp temperature discontinuity. However, this weakly defined discontinuity is maintained during the afternoon due to the absence of turbulence over the sea.

In a recently published high-resolution observational study, Kraus et al. (1990) confirmed the previous results that a given offshore background wind enhances the intensity of the SB front, however, the authors did not specify the conditions for which the intensity of the SB front actually attains its maximum. A tentative interpretation of the observed SB propagation speed can be given by using gravity current theory. Figure 6 depicts schematically a gravity current of thickness $d$, density $\rho_{2}$, and propagation speed $C$ in a fluid of density $\rho_{1}$ moving with velocity $U_{1}$. The gravity current speed equation is given by (Benjamin 1968):

$$
C=F U_{*} ; \quad U_{*}=\left[g\left(\rho_{2}-\rho_{1}\right) / \rho_{1} d\right]^{1 / 2}
$$

where $F$ is an internal Froude number and $U_{*}$ the densimetric speed or the propagation speed of the gravity waves forming at the interface between the two fluids. This equation is valid when $U_{1}=0$. Benjamin (1968) showed that $F$ is a function of the ratio $H / d$. Observational studies (Simpson et al. 1977) and laboratory experiments (Simpson and Britter 1.980) suggest that the Froude number, which is actually a function of the ratio $H / d$ is always close to $2^{-1 / 2}$, whereas Seitter (1986) proposed a value close to 0.79 based upon his analysis of 20 observed gust fronts. This author writes (4) in terms of the surface pressure difference:

$$
C=F\left(\Delta P / \rho_{1}\right)^{1 / 2},
$$

a formulation which eliminates the parameter $d$, which is difficult to estimate. With $\Delta P=0.67 \mathrm{hPa}$ (Table 3 ), $\rho_{1}=1.22 \mathrm{~kg} \mathrm{~m}^{-3}$ and $F=0.79$ the propagation speed is found to be $C=5.9 \mathrm{~m} \mathrm{~s}^{-1}$, a value which gives a fair estimate of the actual SB propagation speed of 5.5 $\mathrm{m} \mathrm{s}^{-1}$. Simpson and Britter (1980) noticed that in the presence of a background wind the actual advance rate of the current is only altered by about 0.6 the value of the geostrophic wind speed. Our results propose a simple superposition of the advance speed of the SB front 

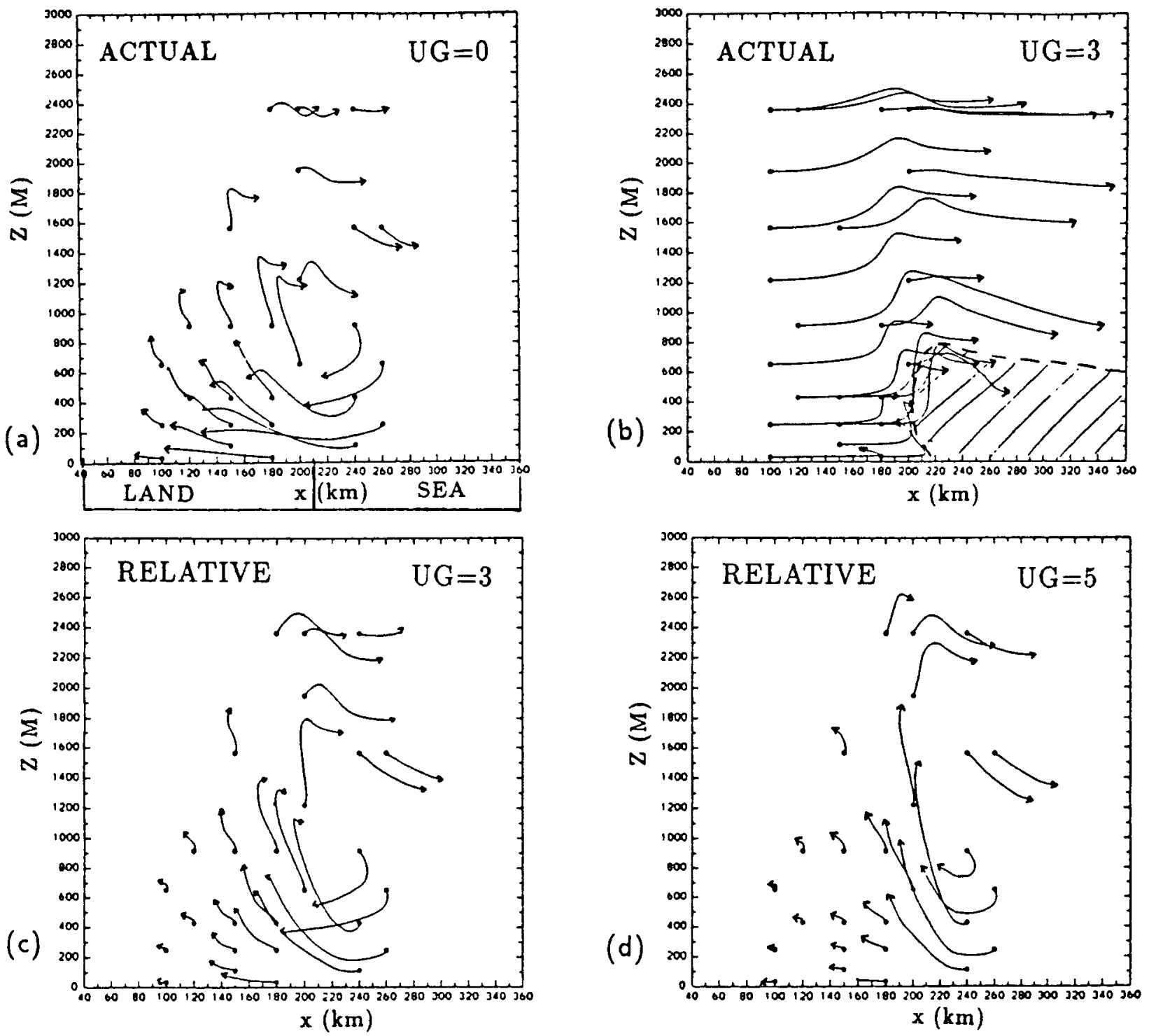

FIG. 4. Twelve-hour trajectories between 0900 and 2100 LST for different values of the geostrophic wind. (a) and (b) actual trajectories, (c) and (d) trajectories in a frame moving with the geostrophic wind.

(i.e., the gravity current) and the geostrophic wind speed. The difference might be due to the coarse horizontal resolution of our model, which does not resolve the head region of the current. Additional numerical simulations (not shown), the results of Rotunno (1983), and Dalu and Pielke (1989) showed that the advance speed of the SB front also depends on the Coriolis parameter. However, both laboratory experiments and model simulations give only rather crude pictures of the real atmosphere, the formulation of a precise stationarity condition for the SB front is out of the scope of this paper.

The conclusions of the present section are therefore twofold: (i) the SB intensity varies with the large-scale wind force and shows a maximum for a $5 \mathrm{~m} \mathrm{~s}^{-1}$ off- shore geostrophic wind, (ii) this maximum is obtained when the propagation speed of the SB front is canceled out by the large-scale flow, leading to a SB front stationary with respect to the coastline.

\section{An inland-breeze case}

Over land, Pinty et al. (1989) have shown that thermally driven circulations, similar to breeze flows, can develop at the boundary between two different types of vegetation cover such as adjacent areas of conifer forest and cereal crops. Similar effects were found for slightly different surface conditions by Segal et al. (1988). The purpose of this section is to investigate the effect of a background wind on this type of inland 

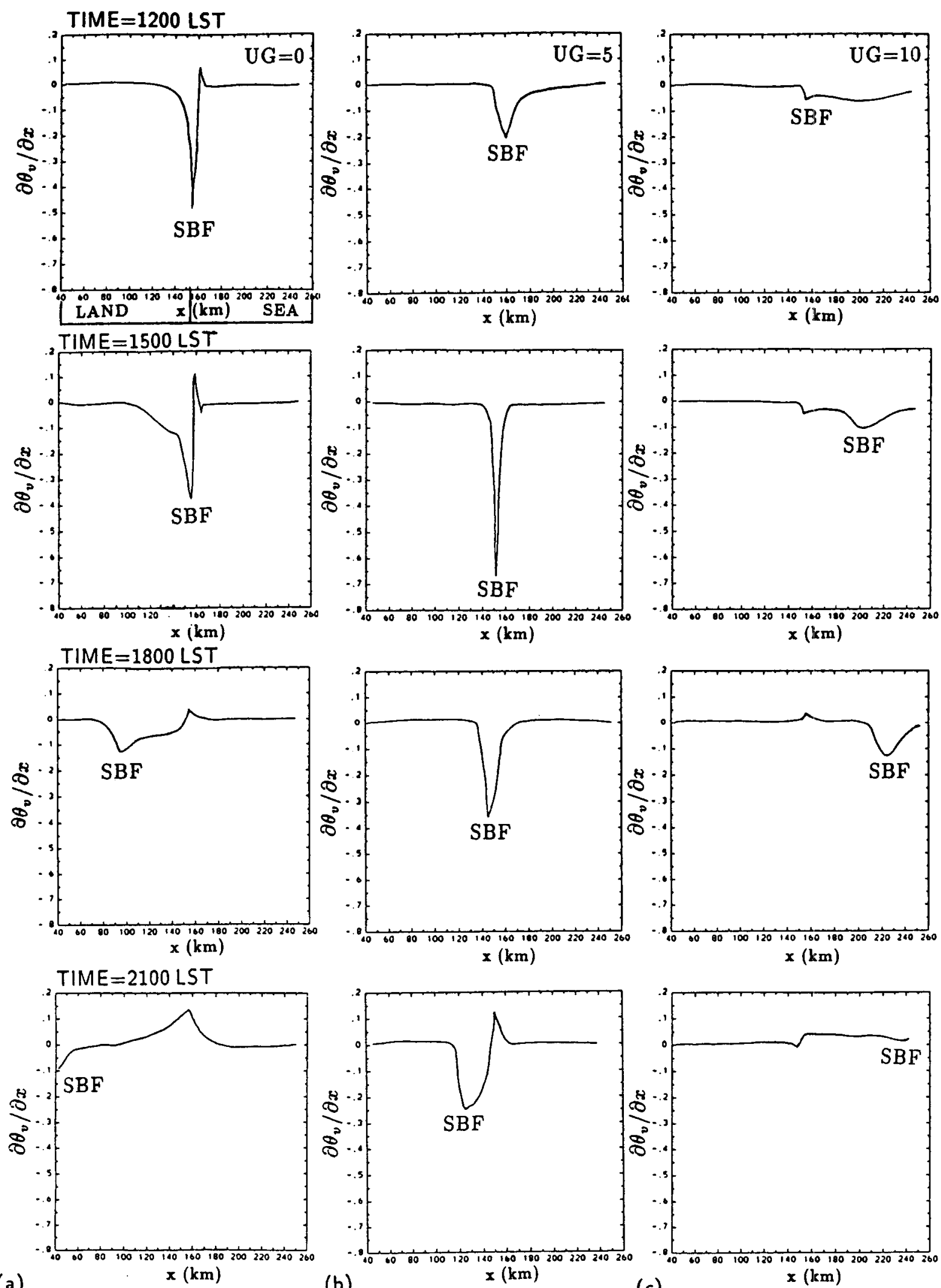

(b)

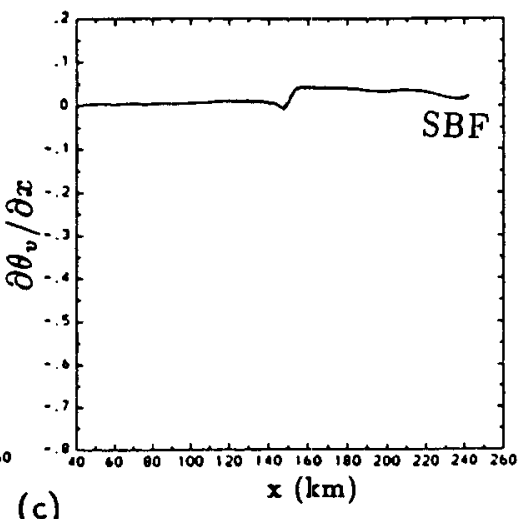

FIG. 5. Evolution and propagation of the sea-breeze front displayed by the horizontal equivalent temperature gradient in kelvins per kilometer for the cases (a) $U_{g}=0 \mathrm{~m} \mathrm{~s}^{-1}$, (b) $U_{g}=5 \mathrm{~m} \mathrm{~s}^{-1}$, and (c) $U_{g}=10 \mathrm{~m} \mathrm{~s}^{-1}$. The location of the sea-breeze front is visualized by the SBF symbol. 
TABLE 2a. Plant parameters: deciduous forest and crops.

\begin{tabular}{llll}
\hline \hline Parameter & Unit & $\begin{array}{c}\text { Deciduous } \\
\text { forest }\end{array}$ & $\begin{array}{c}\text { Mixed } \\
\text { crops }\end{array}$ \\
\hline Height & $\mathrm{m}$ & 15 & 0.7 \\
Albedo & & 0.15 & 0.25 \\
Emissivity & & 0.98 & 0.96 \\
Roughness & $\mathrm{m}$ & 1.25 & 0.06 \\
Displacement & $\mathrm{m}$ & 11 & 0.52 \\
Plant Res. & $\mathrm{s}$ & $8 \times 10^{9}$ & $6 \times 10^{9}$ \\
Min. Sto. Res. & $\mathrm{s} \mathrm{m}{ }^{-1}$ & 350 & 50 \\
Crit. Leaf Pot. & $\mathrm{m}$ & -180 & -100 \\
Green LAI & & 5 & 1.5 \\
Dry LAI & & 1 & 0.2 \\
Shield. Fac. & & 0.9 & 0.8 \\
Rooting depth & $\mathrm{m}$ & 1 & 0.5 \\
Interception & $\mathrm{mm}$ & 1.2 & 0.34 \\
\hline
\end{tabular}

breeze (IB) in an attempt to estimate their possibility of occurrence in the more complex background of real atmospheric conditions. In this section we use the numerical setting of the SB simulations of section 2 and simply replace the land area by a crop area and the sea by a forest. The model is initialized for 0600 LST 16 June. Atmospheric stability is given by $N=0.01 \mathrm{~s}^{-1}$. The soil in both areas is sandy, having a moisture content of 0.17 for the crop area, and 0.22 for the forest and a saturation value of 0.4 . These values were measured in the southwest of France during the HAPEXMOBILHY campaign (André et al. 1986). The albedo and the height of the vegetation were also derived from those measurements. The other vegetation parameters have been taken from the literature (Choudhury and Idso 1985). The plant characteristics are summarized in Table 2a. A detailed description of the soil-vegetation scheme is given in Mahfouf et al. (1987) and Pinty et al. (1989). These authors also reported some numerical simulations of IB. In the following discussion we proceed in the same way as for the SB study. The numerical experiments IB1 and IB2 (Table $2 \mathrm{~b}$ ) of this section correspond to the experiments SB2 and SB4 of section 2.

Figure 7 presents isotachs of the horizontal wind speed $U$ for a zero geostrophic wind case. The circulation is much weaker than the corresponding SB circulation. The atmospheric heating over the crop area is smaller than over the forest owing to the strong latent heat flux associated with the low stomatal resistance

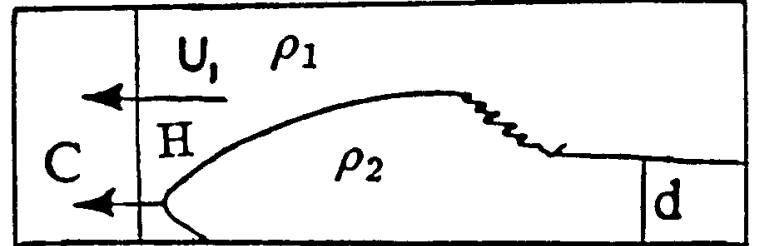

FIG. 6. Schematic representation of a gravity current.

of crops. The low-level wind is therefore directed toward the forest. Figure 8 displays the results of experiment IB1, showing the maximum vertical velocity as a function of the geostrophic wind $U_{g}$. Positive wind speeds correspond to warm advection, that is, offshore winds in the SB case. Maximum vertical velocities are about $4 \mathrm{~cm} \mathrm{~s}^{-1}$, much weaker than for the SB case. The IB intensity remains unchanged over a large range of values $\left(-1 \mathrm{~m} \mathrm{~s}^{-1} \leqslant U_{g} \leqslant 6 \mathrm{~m} \mathrm{~s}^{-1}\right)$. The curve shows no pronounced maximum and is quasi symmetric. The SB study in section 2 has shown that a variation in intensity is related to a propagation of the circulation. Because the intensity of the IB exhibits only a weak dependence on the geostrophic wind, we expect that the IB is stationary.

Following the methodology used in SB4, we characterize the propagation of the IB circulation (experiment IB2) by the displacement of the horizontal virtual temperature gradient minimum, $\partial \theta_{v} / \partial x$. Figure 9 shows the evolution for three selected cases. In all these cases the minimum of $\partial \theta_{v} / \partial x$ does not exceed -0.1 $\mathrm{K} \mathrm{km}^{-1}$ and this minimum is quasi stationary with respect to the interface between the two vegetation types. The temperature gradient minimum is not symmetric with respect to this interface, but extends deeper into the forest area where stronger turbulence is present. Trajectories shown in Fig. 10 for the no-wind case also reveal the influence of turbulence on the IB circulation. The trajectories are more irregular than in the reference SB simulation (Fig. 4a), suggesting that turbulence has some disorganizing effect on the flow.

\section{The role of turbulence}

The SB and the IB cases can be distinguished by both their different intensities and their different propagation behavior. As shown below, these two charac-

TABLE 2b. Inland-breeze simulations.

\begin{tabular}{|c|c|c|c|c|}
\hline Experiment & $U_{g}\left(\mathrm{~m} \mathrm{~s}^{-1}\right)$ & $V_{g}\left(\mathrm{~m} \mathrm{~s}^{-1}\right)$ & $\begin{array}{c}=\left(\frac{g}{\theta} \frac{\partial \theta}{\partial z}\right)^{1 / 2} \\
\left(\mathrm{~s}^{-1}\right)\end{array}$ & $\begin{array}{c}\text { Horizontal } \\
\text { grid size }(\mathrm{km})\end{array}$ \\
\hline IB1 & $\begin{array}{l}-10,-8,-6,-4,-3,-2 \\
-1,0,1,2,3,6\end{array}$ & 0 & 0.01 & 10 \\
\hline IB2 & $-4,0,3$ & $\mathbf{0}$ & 0.01 & 10 \\
\hline
\end{tabular}




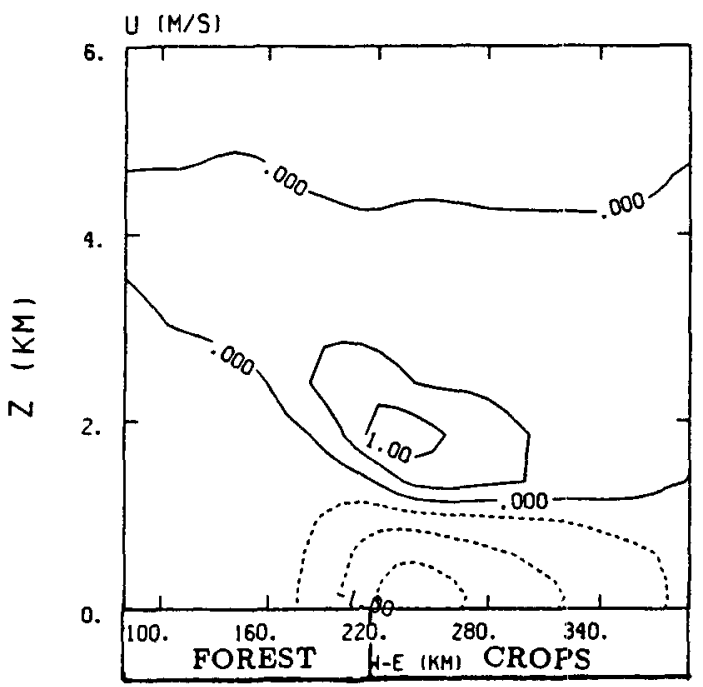

FIG. 7. Isotachs of the horizontal wind speed $U$ in meters per second at 1800 LST with $U_{g}=0 \mathrm{~m} \mathrm{~s}^{-1}$.

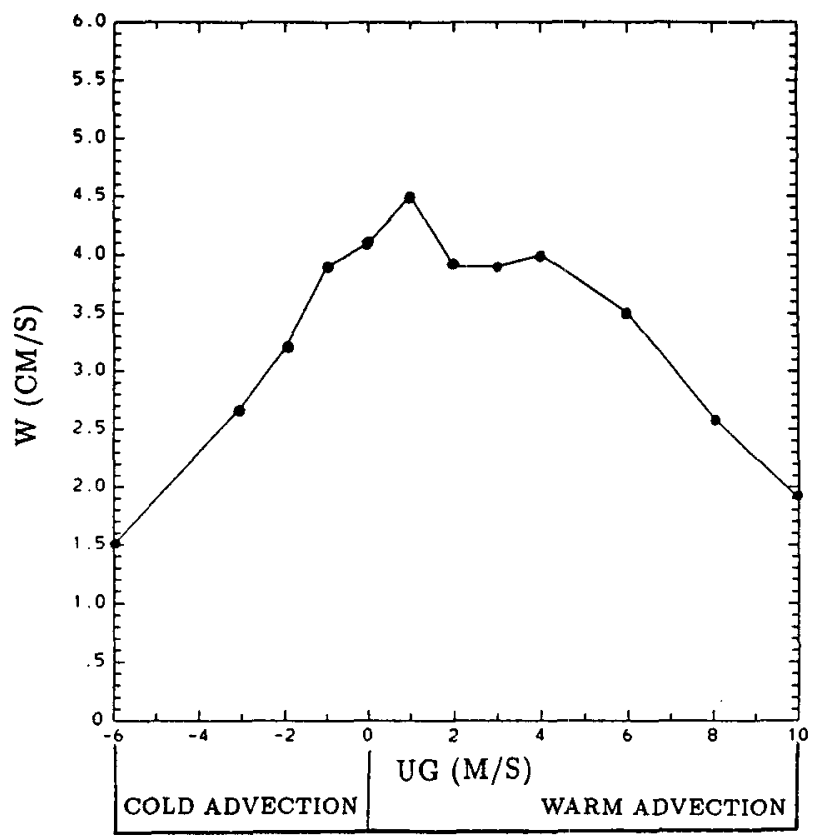

FIG. 8. Vertical velocity in centimeters per second as a function of the geostrophic wind $U_{g}$.
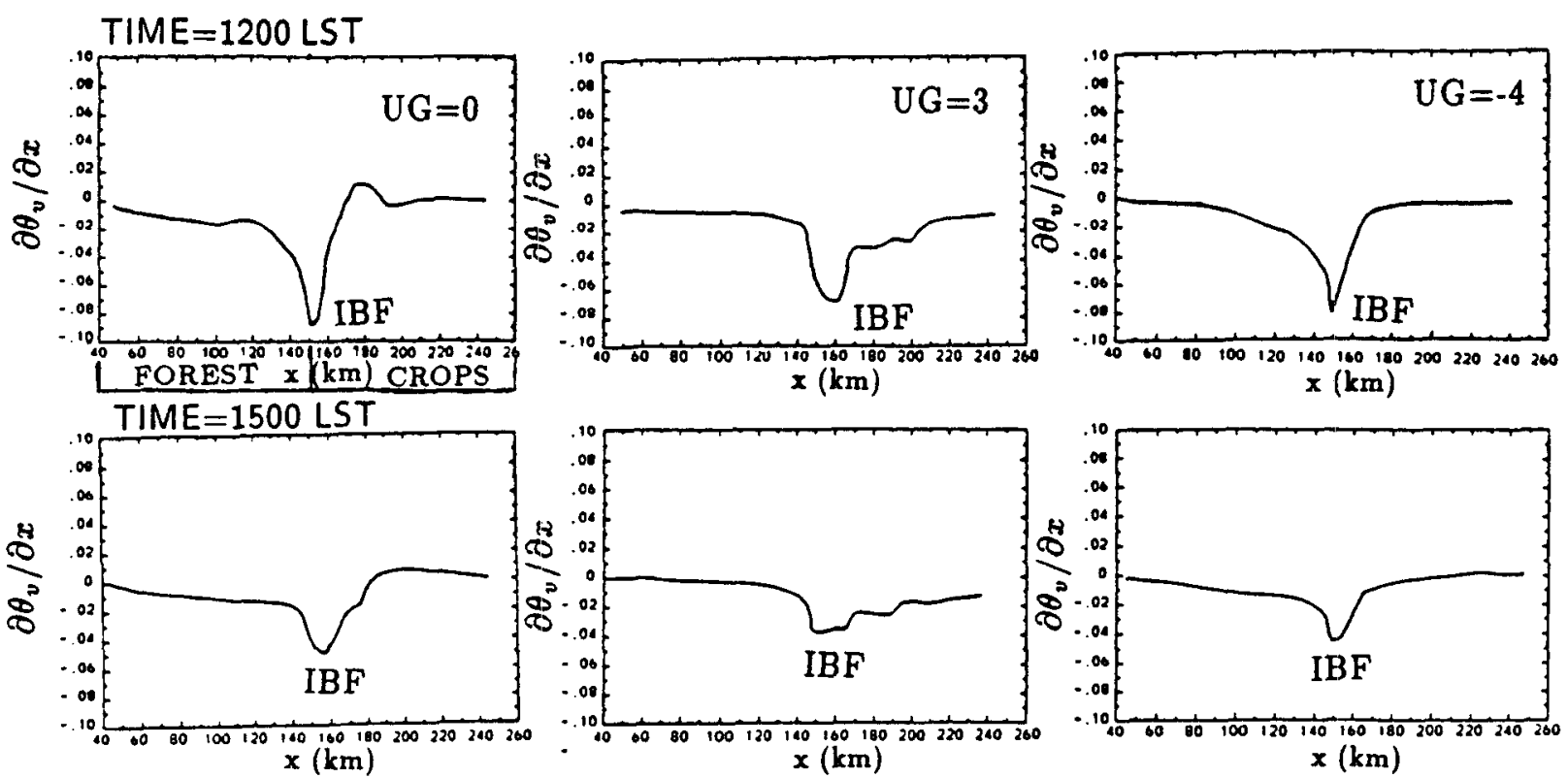

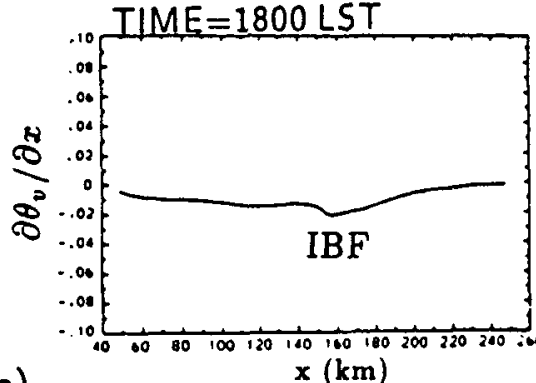

(a)

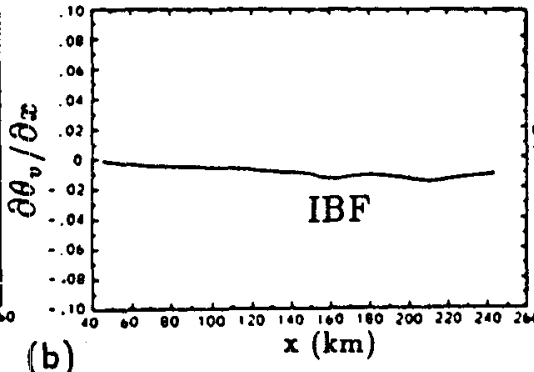

(b)

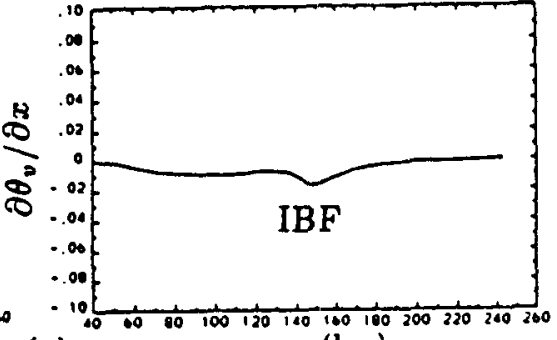

(c) $x(\mathbf{k m})$

FIG. 9. Evolution of the horizontal equivalent temperature gradient in kelvins per kilometer for the cases (a) $U_{g}=0 \mathrm{~m} \mathrm{~s}^{-1}$, (b) $U_{g}=3$ $\mathrm{m} \mathrm{s}^{-1}$, and (c) $U_{g}=-4 \mathrm{~m} \mathrm{~s}^{-1}$. The diffuse inland-breeze front is tentatively located by the IBF symbol. 


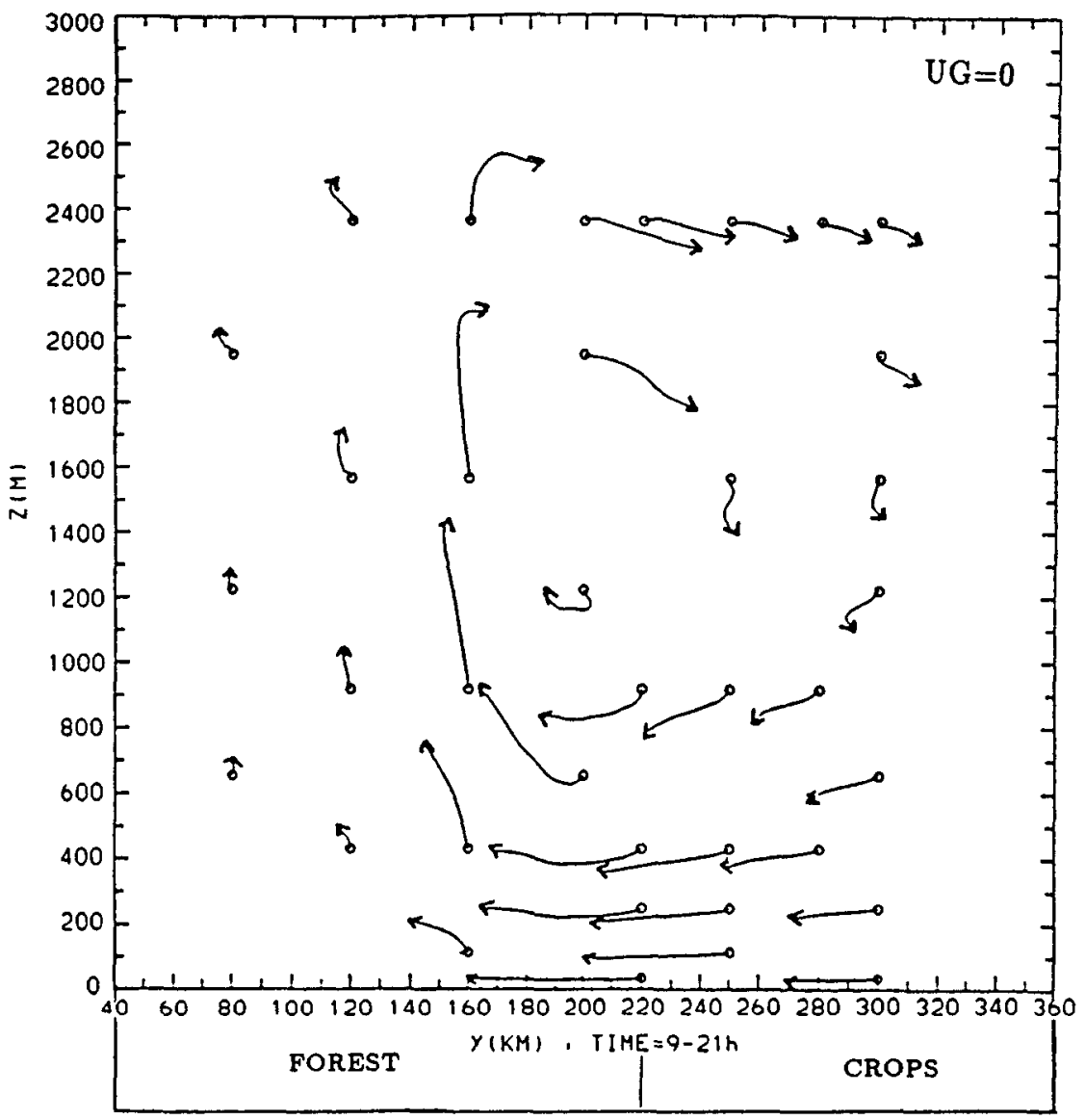

FIG. 10. Twelve-hour trajectories between 0900 and 2100 LST for an inland breeze with $U_{g}=0$.

teristics seem essentially related to the distribution of turbulence over the model domain. Figure 11 shows a comparison between the turbulence field for a no-wind SB case (Fig. 1 1a) and the corresponding IB case. Turbulence is visualized here by the turbulent kinetic energy field. In the SB case, turbulence is confined over the land, whereas, in the IB case turbulence is present over the whole model domain. Maximum temperature and pressure differences across the model domain (Table 3 ) confirm this feature for different model levels. A strong temperature difference of $7 \mathrm{~K}$ exists for the IB at the $z_{0}$ level of the model, that is, just over the ground, but this temperature difference has nearly disappeared aloft, at the first model level near $z=15 \mathrm{~m}$. For the SB, we observe a temperature difference of only $5.3 \mathrm{~K}$ at the $z_{0}$ level, however, the temperature difference does not weaken significantly with altitude, and is still $3.2 \mathrm{~K}$ at $z=15 \mathrm{~m}$. The maximum pressure difference reaches $0.67 \mathrm{hPa}$ at the same level, twice the value for the IB. This comparison suggests that strong and more horizontally uniform turbulent mixing leads to a more uniform temperature field and boundary layer for the IB case. No identifiable breeze front can therefore be found in the IB case, and the gravity current theory does not apply. The surface roughness appears to have a mixing effect (uniform temperature field) rather than a friction effect on the flow.

\section{Conclusions}

We have used a two-dimensional version of the meso- $\beta$ model of Nickerson et al. (1986) in order to study the intensity (vertical velocity) of different thermally driven circulations over flat terrain as a function of the large-scale background wind. We have consid-

TABLE 3. Maximum horizontal temperature and pressure differences as a function of altitude.

\begin{tabular}{llll}
\hline Inland breeze: & $\Delta T_{\infty}=7 \mathrm{~K}$ & $\Delta P_{\infty}=0.34 \mathrm{hPa}$ & $z=z_{0}=0.1 \mathrm{~m}$ \\
& $\Delta T_{\infty}=0.5 \mathrm{~K}$ & $\Delta P_{\infty}=0.34 \mathrm{hPa}$ & $z=15 \mathrm{~m}$ \\
& $\Delta T_{\infty}=0.25 \mathrm{~K}$ & $\Delta P_{\infty}=0.32 \mathrm{hPa}$ & $z=300 \mathrm{~m}$ \\
Sea breeze: & $\Delta T_{\infty}=5.3 \mathrm{~K}$ & $\Delta P_{\infty}=0.67 \mathrm{hPa}$ & $z=z_{0}=0.05 \mathrm{~m}$ \\
& $\Delta T_{\infty}=3.2 \mathrm{~K}$ & $\Delta P_{\infty}=0.67 \mathrm{hPa}$ & $z=15 \mathrm{~m}$ \\
& $\Delta T_{\infty}=2.6 \mathrm{~K}$ & $\Delta P_{\infty}=0.64 \mathrm{hPa}$ & $z=300 \mathrm{~m}$
\end{tabular}



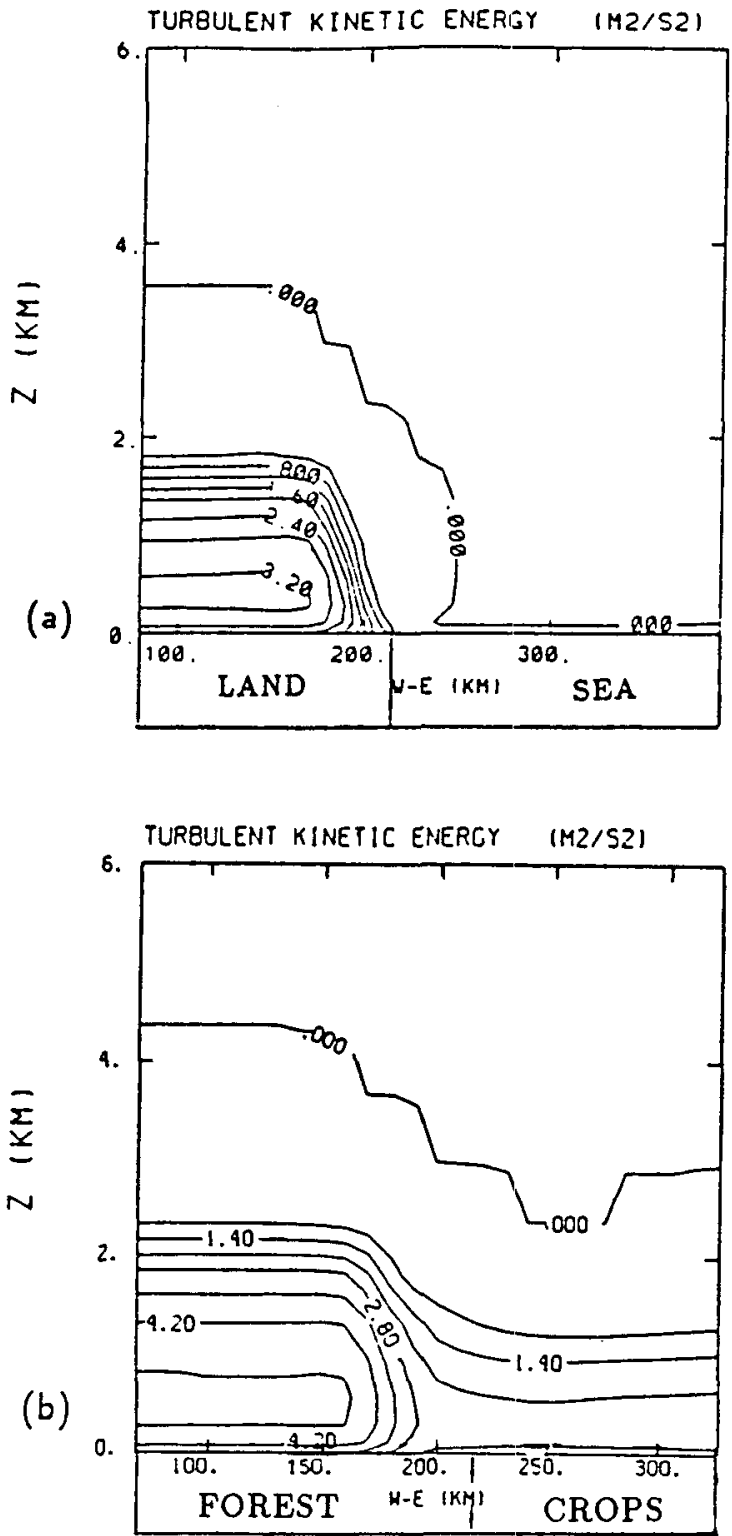

FIG. 11. Vertical cross section of the turbulent kinetic energy field at 1500 LST for (a) a sea-breeze- and (b) an inland-breeze-type circulation.

ered two cases: (i) a sea-breeze case (SB), and (ii) an inland breeze (IB) forming between a forest and an adjacent crop area.

For the SB case, the circulation intensity is only scarcely altered by winds parallel to the coast, but shows significant variations with wind force for off- and onshore wind directions. The maximurn SB intensity is found with a 5-6 $\mathrm{m} \mathrm{s}^{-1}$ offshore background wind when the propagation speed of the SB front is exactly compensated by the large-scale background wind, leading to a SB front stationary with respect to the coastline. A schematic analytical model of the process, using the gravity current theory, gives a fair prediction of this optimum background wind value.

The IB revealed a fundamentally different behavior. The intensity and extent of the breeze does not vary over a wide range of values for the background wind $\left(-1 \mathrm{~m} \mathrm{~s}^{-1} \leqslant U_{g} \leqslant 6 \mathrm{~m} \mathrm{~s}^{-1}\right)$. Positive wind speeds correspond to warm advection, that is, offshore winds in the SB case. This behavior leads us to believe that a vegetation breeze may actually be observed. The particular characteristics of the IB circulation seem related to the turbulence, which is present over the whole model domain. Turbulence leads to a more horizontally uniform boundary layer in spite of the strong temperature differences existing at the canopy level.

Acknowledgments. Our gratitude specially goes to Professor R. Rosset, Dr. E. Nickerson, and an anonymous referee for their helpful comments and suggestions. We are indebted to J. Duron, who developed the graphic software and solved many computer problems. This work was supported by grants from Electricité de France and Institut National des Sciences de l'Univers (Program Atmospheric Métérology). Computer resources have been made available by CCVR (Palaiseau, France). Access to the computer network was provided by CNUSC (Montpellier, France).

\section{APPENDIX}

\section{List of Symbols}

C gravity current speed

$d \quad$ gravity current thickness

$f \quad$ Coriolis parameter

$F \quad$ Froude number

$F_{u}, F_{v}$ vertical divergences of the turbulent fluxes

$g \quad$ acceleration of gravity

$H$ thickness of the ambiant fluid

$N \quad$ Brunt-Väisälä frequency

$P \quad$ pressure

$P_{s} \quad$ soil pressure

$P_{\text {top }}$

$R$

$T$

$T_{v}$

$U$

$U_{g}$

$U_{1}$

$U_{*}$

$u_{*}$

$V$

pressure at the top of the model $=300 \mathrm{hPa}$

gas constant for dry air

temperature

virtual temperature

wind component in the $x$ direction

geostrophic wind in the $x$ direction

velocity of the ambiant fluid

densimetric speed

friction velocity

wind component in the $y$ direction

geostrophic part of $V$

vertical velocity

horizontal coordinate (positive eastward)

horizontal coordinate (positive northward)

vertical coordinate

roughness length

total horizontal temperature difference

total horizontal pressure difference 
$\theta_{v} \quad$ virtual potential temperature

$\nu \quad$ transformed vertical coordinate

$\dot{\nu} \quad$ vertical velocity in the transformed vertical coordinate

II pressure difference between the bottom and the top of the model

$\sigma \quad$ vertical coodinate $\sigma=\sigma(\nu)$

$\sigma^{\prime} \quad d \sigma / d \nu$

$\rho$ density

$\Phi$ geopotential

\section{REFERENCES}

André, J.-C., J.-P. Goutorbe and A. Perrier, 1986: HAPEX-MOBILHY: A hydrological atmospheric experiment for the study of water budget and evaporation flux at the climatic scale. Bull. Amer. Meteor. Soc., 67, 138-144.

Arrit, R. W., 1989: Numerical modelling of the offshore extent of sea breezes. Quart. J. Roy. Meteor. Soc., 115, 547-570.

Benjamin, T. B., 1968: Gravity currents and related phenomena. $J$. Fluid Mech., 31, 209-248.

Choudhury, B. J., and S. B. Idso, 1985: Evaluating plant and canopy resistances of field-grown wheat from concurrent diurnal observations of leaf water potential, stomatal resistance, canopy temperature, and evapotranspiration flux. Agric. For. Meteorol., $34,67-76$.

Dalu, G. A., and R. A. Pielke, 1989: An analytical study of the sea breeze. J. Atmos. Sci., 46, 1815-1825.

Defant, F., 1951: Compendium of Meteorology. Amer. Meteor. Soc., 658-672.

Estoque, M. A., 1962: The sea breeze as a function of the prevailing synoptic situation. J. Atmos. Sci., 19, 244-249.

Kraus, H., J. M. Hacker and J. Hartmann, 1990: An observational aircraft-based study of sea-breeze frontogenesis. Bound.-Layer Meteor., 26, 223-265.
Mahfouf, J. F., E. Richard and P. Mascart, 1987: The influence of soil and vegetation on the development of mesoscale circulations. J. Climate Appl. Meteor., 26, 1671-1695.

Nickerson, E. C., E. Richard, R. Rosset and D. R. Smith, 1986: The numerical simulation of clouds, rain, and airflow over the Vosges and Black Forest mountains: A meso- $\beta$ model with parameterized microphysics. Mon. Wea. Rev., 114, 398-414.

Ookouchi, Y., M. Segal, R. C. Kessler and R. A. Pielke, 1984: Evaluation of soil moisture effects on the generation and modification of mesoscale circulations. Mon. Wea. Rev., 112, 2281-2292.

Pinty, J. P., P. Mascart, E. Richard and R. Rosset, 1989: An investigation of mesoscale flows induced by vegetation inhomogeneities using an evapotranspiration model calibrated against HAPEX-MOBILHY data. J. Appl. Meteor., 28, 976-992.

Rotunno, R., 1983: On the linear theory of the land and sea breeze. J. Atmos. Sci., 40, 1999-2009.

Savijärvi, H., and M. Alestalo, 1988: The sea breeze over a lake or gulf as the function of the prevailing flow. Beitr. Phys. Atmosph., 61, 98-104.

Segal, M., R. Avissar, M. C. McCumber and R. A. Pielke, 1988: Evaluation of vegetation effects on the generation and modification of mesoscale circulations. J. Atmos. Sci., 45, 2268-2292.

Seitter, K. L., 1986: A numerical study of atmospheric density current motion including the effects of condensation. J. Atmos. Sci., 43, 3068-3076.

Simpson, J. E., and R. E. Britter, 1980: A laboratory model of an atmospheric mesofront. Quart. J. Roy. Meteor. Soc., 106, 485500 .

_, D. A. Mansfield and J. R. Milford, 1977: Inland penetration of sea-breeze fronts. Quart. J. Roy. Meteor. Soc., 103, 47-76.

Therry, G., and P. Lacarrere, 1983: Improving the eddy kinetic energy model for planetary boundary layer description. Bound.-Layer Meteor., 25, 63-88.

Walsh, J. E., 1974: Sea-breeze theory and applications. J. Atmos. Sci., 31, 2012-2026.

Yan, H., and R. A. Anthes, 1987: The effect of latitude on the sea breeze. Mon. Wea. Rev., 115, 936-956. 